\title{
Two-colour immunoenzymatic technique using sequential staining by APAAP to evaluate two cell antigens
}

\author{
R Burgess, K Hyde, P J Maguire, P R Kelsey, J A Liu Yin, C G Geary
}

University

Department of

Clinical and

Laboratory

Haematology,

Manchester Royal

Infirmary, Oxford

Road, Manchester

M13 9WL

R Burgess

K Hyde

P J Maguire

$\mathrm{J}$ A Liu Yin

C G Geary

Department of Haematology, Victoria Hospital, Blackpool P R Kelsey

Correspondence to: Mr R Burgess

Accepted for publication 27 August 1991

\begin{abstract}
Aims: To extend the alkaline phosphatase-antialkaline phosphatase (APAAP) immunoenzyme single stain method to a more generally applicable double stain technique. This will allow two primary antibodies of the same isotype of IgG and specifically the nuclear antigen bromodeoxyuridine (BRdU) to be evaluated with a cell surface antigen identifier.

Method: Sequential applications of the APAAP method showed two antigen sites by different dye couplings to a common alkaline phosphatase substrate, producing blue and red reaction products on the same slide. Antigens on different cell populations as well as those in different compartments of the same cell were analysed. The method allowed a surface antigen monoclonal to be revealed first, using an optimal fixative, before alcohol/ gluteraldehyde fixation was used to start the second (BRdU) staining sequence.

Results: An analysis of double staining of T lymphocyte subsets (CD4 and CD8) showed no significant difference in the order of application of the primaries $(n=$ 10) and no significant difference from their corresponding single stain results (n $=50$ ), confirming the validity of the technique where antigens are exclusively distributed. Other examples, including antigens distributed in different compartments of the same cell, displayed discrete staining which implied validity. Conclusion: Double staining by APAAP with this technique seems to be applicable to those cases where antigens are exclusively distributed and includes cases where different compartments of the same cell are stained. It is especially useful in revealing antigens that require different fixation and preparation-that is DNA incorporated BRdU with a surface antigen. But it does seem to have a limited ability to produce a dual colour at a common site.
\end{abstract}

Immunocytochemical techniques for the demonstration of leucocyte antigens in conventional blood and marrow smears are well established procedures and within the scope of most laboratories. But the availability of double immunoenzyme methods is less widespread.

Double immunoenzymatic staining was first performed using an indirect immunoperoxidase technique with elution of antibody of the first sequence before proceeding to the second stage. ${ }^{1}$ The removal of antibody without damaging the antigens of interest was subsequently avoided, either by utilising the protective effect of the first peroxidase substrate reaction product, ${ }^{2}$ or by using primary antibody pairs of unrelated species. ${ }^{3-6}$

Several double immunostaining techniques have been described using combinations of peroxidase, alkaline phosphatase, fluorescence and gold colloid for labelling, often incorporating direct conjugation, ${ }^{7-11}$ or different subclasses, or isotype primaries. ${ }^{12}$ As alkaline phosphatase seems to be the label of choice for many haematology laboratories the role of sequential double staining using the indirect alkaline phosphatase-antialkaline phosphatase (APAAP) technique was investigated. ${ }^{13}$

Sequential double staining by APAAP for separate cell populations using different substrates has been described..$^{14}$ We extended the method to: incorporate dual staining of a single cell; report increased clarity of the stained product; and confirm its validity statistically.

The primary antibodies used were class IgG of mouse origin, and the APAAP complex and bridging reagents were the same for both sequences. Different dye couplings to a common substrate, producing contrasting colours of blue and red, were used for each sequence.

The analysis of $\mathrm{T}$ lymphocyte subsets in normal peripheral blood was initially chosen as a suitable model. CD4 and CD8 antigens are generally exclusively distributed and the distribution well defined. ${ }^{15}$ Clinical applications of the technique, giving examples of other antigen pairs, including antigens present on the same cell, have also been described.

\section{Methods}

Cell smears of EDTA anticoagulated peripheral blood from 50 plasmapheresis donors (26 males and 24 females) with normal blood cell variables were used for the initial study. Smears were allowed to dry overnight and stored, wrapped in aluminium foil at $-20^{\circ} \mathrm{C}$, before staining. Further studies were performed on cytospin preparations of light density mononuclear cells. 
Table 1 List of primary antibodies used

\begin{tabular}{|c|c|c|c|}
\hline \multicolumn{4}{|c|}{ Primary monoclonal antibodies } \\
\hline $\begin{array}{l}\text { Antigen } \\
\text { T helper } \\
\text { T suppressor } \\
\text { Glycoprotein IIIa } \\
\text { Macrophage } \\
\text { Transferrin Rec } \\
\text { Bromodeoxyuridine } \\
\text { Myeloperoxidase } \\
\kappa \text { light chain }\end{array}$ & $\begin{array}{l}\text { Cluster } \\
\text { CD4 } \\
\text { CD8 } \\
\text { CD61 } \\
\text { CD68 } \\
\text { CD71 }\end{array}$ & $\begin{array}{l}\text { Clone } \\
\text { RFT4 } \\
\text { RFT8 } \\
\text { Y2/51 } \\
\text { EMB11 } \\
\text { Ber-T9 } \\
\text { Bu20a } \\
\text { MPO-7 } \\
\text { A8B5 }\end{array}$ & $\begin{array}{l}\text { Manufacturer } \\
\text { Royal Free Hospital } \\
\text { Royal Free Hospital } \\
\text { DAKO } \\
\text { DAKO } \\
\text { DAKO } \\
\text { DAKO } \\
\text { DAKO } \\
\text { DAKO }\end{array}$ \\
\hline
\end{tabular}

Details of the monoclonal antibodies used in the study are given in table 1 . Other reagents were as previously reported, ${ }^{16}$ with the addition of a further fast dye (Fast Blue BB salt; Sigma Chemicals, Code 3378) to contrast with the Fast Red salt used in the single stain procedure. The double stain method is outlined in table 2 and shows the Fast Blue salt used as the first dye. We found that the results were clearer when we used this order. Good results were also found without attempting to block remaining antigenic sites of the first sequence.

Stained slides were examined under a $\times 540$ magnification. Absolute values of CD4 and CD8 positive lymphocytes were calculated from manual estimations of positive lymphoid cells as a fraction of the total white cell count, established by electronic counter, for both the single and double staining procedures. Preliminary investigations of lymphocyte subset estimates showed no significant differences in the order of application of monoclonal antibodies ( $\mathrm{n}=10 ; \mathrm{CD} 4: \mathrm{p}=0.3$; CD8: $\mathrm{p}=$ $0 \cdot 1$ ) and detailed comparisons between single and the double staining techniques were then performed.

Nuclear incorporation of bromodeoxyuridine (BRdU) was performed using standard methodology ${ }^{17} 18$ and staining was always performed as a second sequence. This allowed the first staining sequence to be completed without regard for antigen preservation during DNA denaturation. A further fixation step prior to denaturation was found to be necessary as

Table 2 Double stain procedure

1 Fix cells (appropriate for the first and to conserve the second antigen)

Apply first primary antibody (mouse monoclonal)

3 Apply polyclonal antimouse 'bridge'

3 Apply polyclonal antimouse 'bridge'

Apply APAAP conjugate (mouse)

Repeat steps 3 and 4 if necessary
Apply substrate using Fast Blue BB salt

Apply substrate using Fast Blue BB salt

Apply second primary antibody (mouse)

9 Apply polyclonal antimouse 'bridge'

10 Apply APAAP conjugate (mouse)

11 Repeat steps 9 and 10 if necessary

12 Apply substrate using Fast Red

Notes:

Fixation: Usually half and half acetone/methanol (90 seconds). A second fixation step is not normally necessary.

BRdU sequence performed after 15 minutes fixation in a solution of: $\left(70 \% \mathrm{EtOH}+30 \% \mathrm{H}_{2} \mathrm{O}\right)$ $+0.25 \%$ gluteraldehyde followed by denaturation for two minutes in $0.07 \mathrm{M} \mathrm{NaOH}$, giving brief washes in saline before and after denaturation step.

Incubation: 20-25 minutes each unless otherwise evaluated, with brief washes in buffer between each step.

The "repeat" incubations (Nos 5 and 11) are 10 minutes each.

Substrate incubations (Nos 6 and 12) are 15 minutes each.

Substrate: Fast Blue BB salt is at $5 \mathrm{mg}$ per $10 \mathrm{ml}$ substrate Fast Red TR salt is at $10 \mathrm{mg}$ per $10 \mathrm{ml}$ substrate. standard fixatives could not adequately maintain good morphology during this procedure. This prompted the use of an enhanced fixative (table 2).

\section{Results}

Air dried cell smears from 50 donors, stained for both CD4 and CD8, in the double staining procedure showed clear and discrete staining (fig 1) and showed no significant differences from the corresponding single stains $(n=50$ CD4: $p=0.3$; CD8: $p=0.3$ ), producing reference ranges (CD4: $0.43-1.79 \times 10^{9} / 1$. CD8: $0 \cdot 13-1.01 \times 10^{9} / 1$.) that corresponded closely with published values. ${ }^{19-21}$

Other double staining combinations where antigens are exclusively distributed (figs 2 and 3) were analysed qualitatively and showed a clarity of discreet staining and morphological compatibility that suggested validity.

Use of the procedure to stain different regions of the same cell, such as the nucleus and membrane, seemed to work for the case where BRdU was the nuclear antigen under investigation (fig 4). We showed that this process depleted the functional activity of alkaline phosphatase (from the first staining sequence) and, as reported elsewhere, ${ }^{12}$ also noted the denaturation of a range of antigens on cells. The observation that the Fast Blue dye would not stain APAAP labelled nuclear antigens using this method also needed to be borne in mind.

\section{Discussion}

The advantages of immunoenzyme over immunofluorescence techniques have already been discussed. ${ }^{22-25}$ They include a permanent preparation of the labelled specimen, increased morphological resolution of both labelled and unlabelled cells, a lack of cell subset distortion in the case of lymphocyte subsets, and an ease of handling specimens obtained from no more than a few drops of blood or marrow. The simultaneous demonstration of two antigens in the same preparation shares these advantages. It also allows direct observations of the relative frequency of expression to be made and can also evaluate the spatial relations of such cells.

Wagner and Worman have reported a similar staining technique using only CD4 and CD8 antigens. ${ }^{14}$ The improved clarity of staining with our methodology for a range of monoclonal antibodies, its statistical validity, and the way in which the technique can be extended to include dual staining of single cells using BRdU as the nuclear antigen greatly increases its possible applications.

Within the reported limitations of the procedure $^{24}$ (both stains needing to be of equal intensity), parallel same-site double immunoenzymatic staining can be done, ${ }^{3-6}$ but like others who used sequential techniques, ${ }^{1014}$ we were unable to develop the method to this degree. Although the sequential staining process is more time consuming than parallel immunoenzyme systems, it requires no methodological development, can be used to 


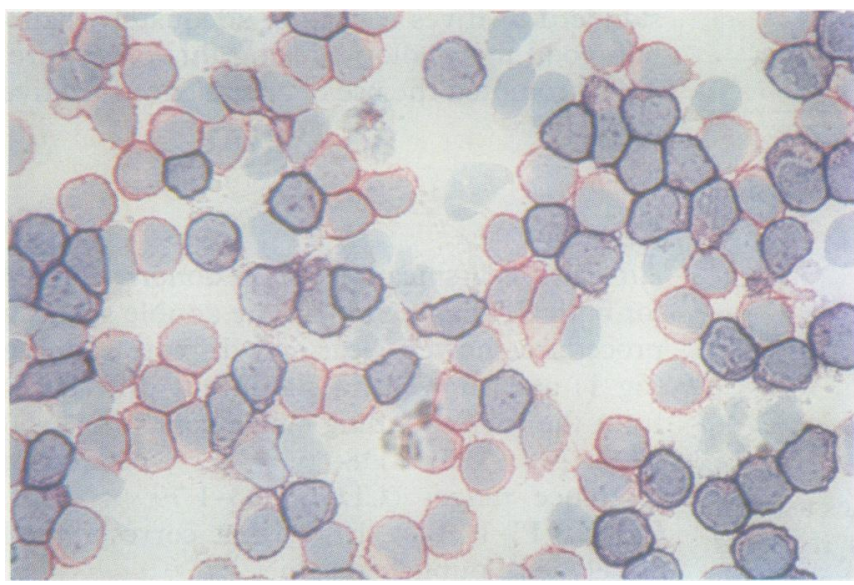

Figure 1 Cytospin preparation. Normal light density blood cells. Staining: CD8 (suppressor cell) blue; $C D 4$ (helper cell) red.

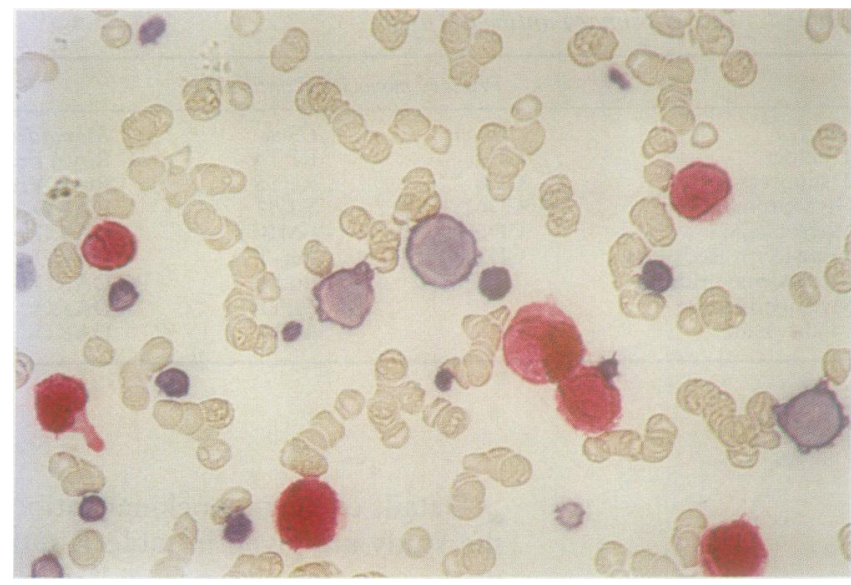

Figure 2 Peripheral blood smear: chronic granulocytic leukaemia in transformation. Staining: CD61 (platelet glycoprotein IIIa) blue; myeloperoxidase red.

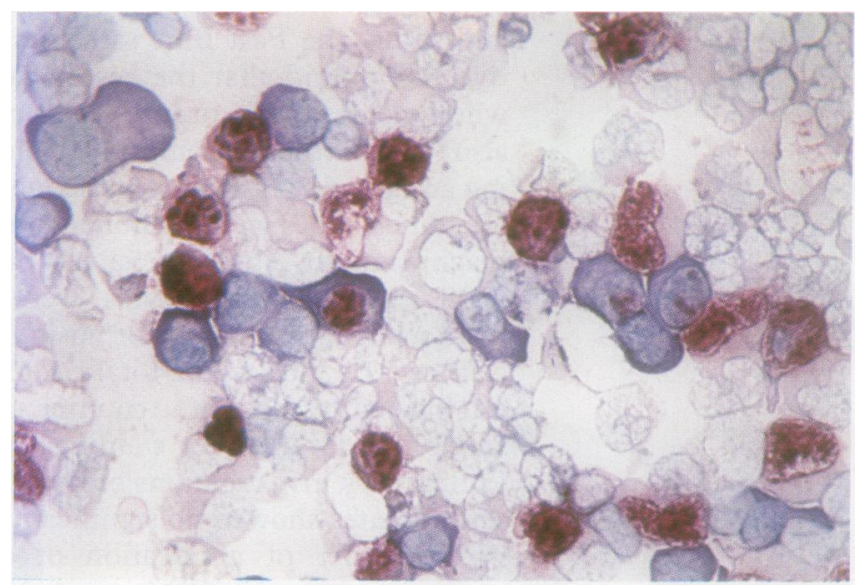

Figure 4 Cytospin preparation: light density bone marrow cells from a myeloma at presentation, after four hours' in vitro incubation with $B R d U$. Staining: $\kappa$ light chain blue; $B R d U$ red.

Figure 3 Cytospin preparation: Suspension culture of light density
marrow cells: an acute myeloid leukaemia with increased erythroid component. Staining: CD68 (macrophage) blue; CD71 (transferrin receptor) red.

analyse pairs of antigens that require different preparation (such as BRdU and surface membrane antigens), and, moreover, can utilise the same isotype mouse monoclonal antibodies for both primaries. The double stain procedure, incorporating the nuclear antigen BRdU to analyse proliferative fractions of a cell lineage, has previously been performed by fluorescence double stain techniques ${ }^{12182627}$ and has wide applications.

This technique seems to be well suited to those cases where cell antigens are exclusively distributed. It may also be applied to cases of single cell dual staining where the two antigens are localised in different compartments, such as the nucleus and membrane. This technique can also be used in other haematological studies. Our results show that double staining using the APAAP technique can produce good results, and moreover can be applied in any laboratory where the single stain method is in use.

1 Nakane PK. Simultaneous localization of multiple tissue antigens using the peroxidase-labelled antibody method: A study on pituitary glands of the rat. $J$ Histochem Cytochem 1968;16:557-60.

2 Sternberger LA, Joseph SA. The unlabelled antibody method: Contrasting color staining of paired pituitary
hormones without antibody removal. $J$ Histochem Cytochem 1979;27:1424-9.
3 Mason DY, Sammons RE. Alkaline phosphatase and peroxidase for double immunoenzymatic labelling of cellula constituents. J Clin Pathol 1978;31:454-60.

4 Campbell GT, Bhatnagar AS. Simultaneous visualization by light microscopy of two pituitary hormones in a single tissue section using a combination of indirect immunohistochemical methods. J Histochem Cytochem 1976;24: tochemical 4 -52.

5 Mason DY, Stein H. Reactive and neoplastic human lymphoid cells producing $\mathrm{J}$ chain in the absence of immunoglobulin: evidence for the existence of "J chain disease"? Clin Exp Immunol 1981;46:305-12.

6 Mason DY, Stein H, Naiem M, Abdulaziz. Immunohistological analysis of human lymphoid tissue by double immunoenzymatic labelling. J Cancer Res Clin Oncol 1981;101:13-22.

7 Namikawa R, Ueda R, Suchi T, Itoh G, Ota K, Takahashi $T$. Double immunoenzymatic detection of surface phenotype of proliferating lymphocytes in situ with monoclonal antibodies against DNA polymerase (alpha) and lymphocyte membrane antigens. A J Clin Pathol 1987;87: phocyte

8 Neame PB, Soamboonsrup P, Browman G, et al. Simultaneous or sequential expression of lymphoid and myeloid phenotypes in acute leukaemia. Blood 1985;65:142-8.

$9 \mathrm{Gu}$ J, De May J, Moeremans M, Polak J. Sequential use of the PAP and immunogold staining methods for the light microscopical double staining of tissue antigens. Reg Peptides 1981;1:365-74.

10 Falini B, Abdulaziz Z, Gerdes J, et al. Description of a sequential staining procedure for double immunoenzymatic staining of pairs of antigens using monoclonal antibodies. $J$ Immunol Methods 1986;93:265-73.

11 Falini B, De Solas I, Halverson C, Parker JW, Taylor CR. Double labelled-antigen method for demonstration of intracellular antigens in paraffin-embedded tissue. $J$ Histochem Cytochem 1982;30:21-6.

12 Campana D, Coustan-Smith E, Janossy G. Double and triple staining methods for studying the proliferative activity of human $B$ and $T$ lymphoid cells. I Immunol Methods 1988;107:79-88.

13 Cordell JL, Falini B, Erber WN, et al. Immunoenzymatic labelling of monoclonal antibodies using immune complexes of alkaline phosphatase and monoclonal anti-alk- 
aline phosphatase. J Histochem Cytochem 1984;32:219-29. 14 Wagner L, Worman CP. Color-contrast staining of two different lymphocyte subpopulations: A two-color modification of alkaline phosphatase monoclonal anti-alkaline phosphatase complex technique. Stain Technol 1988;63: 129-35.

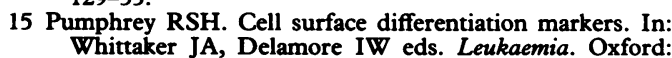
Blackwell Scientific Publications, 1988:152-83.

16 Mason DY. Immunocytochemical labelling of monoclonal antibodies by the APAAP immunoalkaline phosphatase technique: In: Bullock GR, Petrusz P, eds. Technniques in immunocytochemistry Vol 3. New York: Academic Press, 1988:25-42.

17 Gratzer HG. Monoclonal antibody to 5-bromo and 5 iododeoxyuridine: a new reagent for detection of DNA iododeoxyuridine: a new reagent for

18 Lokhorst HM, Boom SE, Bast BJEG, Ballieux RE. Determination of the plasma cell labelling index with bromodeoxyuridine in a double fluorescence technique. Br J Haematol 1986;64:271-5.

19 Goff LK, Habeshaw JA, Rose ML, Gracie JA, Gregory W. Normal values for the different classes of venous blood mononuclear cells defined by monoclonal antibodies. $J$ Clin Pathol 1985;38:54-9.

20 Wong GKW, Hui PK, Ng WL, Leong SL. Enumerating T cell subsets on blood smears: An evaluation of an indirect immunoalkaline phosphatase method. Am J Clin Pathol 1986;86:756-9.

21 Erber WN, Pinching AJ, Mason DY. Immunocytochemical detection of $T$ and $B$ cell populations in routine blood smears. Lancet 1984;1042-6.

22 Iwatani Y, Amino N, Mori $\mathrm{H}$, et al. Effects of various isolation methods for human peripheral lymphocytes on $\mathrm{T}$ cell subsets determined in a fluorescence activated cell sorter (FACS), and demonstration of a sex difference of suppressor/cytotoxic T cells. J Immunol Methods 1982; 54:31-42.

23 Moir DJ, Ghosh AK, Abdulaziz Z, Knight PM, Mason DY. Immunoenzymatic staining of haematological samples with monoclonal antibodies. Br J Haematol 1983;55: 395-410.

24 Mason DY, Woolston RE. Double immunoenzymatic labelling techniques in immunocytochemistry. In: labelling techniques in immunocytochemistry. In: cytochemistry. Vol 1. New York: Academic Press, 1982: cytochemist

25 Staquet MJ, De Fraissinette A, Dezutter-Dambuyant C, Schmitt D, Thivolet J. A combined method for detection of cell surface marker expression and bromodeoxyuridine (BrdU) uptake by epidermal cells in suspension. $J$ Immunol Methods 1989;116:287-92.

26 De Fraissinette A, Staquet MJ, Dezutter-Dambuyant C, Schmitt D, Thivolet J. Langerhans cells in S-phase in normal skin detected by simultaneous analysis of

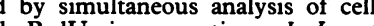
surface antigen and $\mathrm{BrdU}$ incorporation.

atol 1988;91:603-5.

Campana D, Janossy G. Proliferation of normal and malignant human immature lymphoid cells. Blood 1988;71: 1201-10. 